\title{
Simultaneous detection of Plasmodium vivax and Plasmodium falciparum gametocytes in clinical isolates by multiplex-nested RT-PCR
}

\author{
Napaporn Kuamsab, Chaturong Putaporntip, Urassaya Pattanawong and Somchai Jongwutiwes*
}

\begin{abstract}
Background: Gametocyte carriage is essential for malaria transmission and endemicity of disease; thereby it is a target for malaria control strategies. Malaria-infected individuals may harbour gametocytes below the microscopic detection threshold that can be detected by reverse transcription polymerase chain reaction (RT-PCR) targeting gametocyte-specific mRNA. To date, RT-PCR has mainly been applied to the diagnosis of Plasmodium falciparum gametocytes but very limited for that of Plasmodium vivax.

Methods: A multiplex-nested RT-PCR targeting Pfs 25 and Pvs25 mRNA specific to mature gametocytes of $P$. falciparum and $P$. vivax, respectively, was developed. The assay was evaluated using blood samples collected in rainy and dry seasons from febrile patients,in a malaria-endemic area in Thailand. Malaria diagnosis was performed by Giemsa-stained blood smears and 185 rRNA PCR.

Results: The multiplex-nested RT-PCR detected Pfs 25 mRNA in 75 of 86 (87.2\%) P. falciparum-infected individuals and Pvs 25 mRNA in 82 of 90 (91.1\%) P. vivax malaria patients diagnosed by 185 rRNA PCR. Gametocytes were detected in 38 (eight $P$. falciparum and 30 P. vivax) of 157 microscopy positive samples, implying that a large number of patients harbour sub-microscopic gametocytaemia. No seasonal differences in gametocyte carriage were observed for both malaria species diagnosed by multiplex-nested RT-PCR. With single-nested RT-PCR targeting Pfs 25 or Pvs 25 mRNA as standard, the multiplex-nested RT-PCR offered sensitivities of $97.4 \%$ and $98.9 \%$ and specificities of $100 \%$ and $98.8 \%$ for diagnosing mature gametocytes of $P$. falciparum and $P$. vivax, respectively. The minimum detection limit of the multiplex-nested PCR was 10 copies of templates.

Conclusions: The multiplex-nested RT-PCR developed herein is useful for simultaneous assessment of both $P$. falciparum and $P$. vivax gametocyte carriage that is prevalent and generally sympatric in several malaria-endemic areas outside Africa.
\end{abstract}

Keywords: Malaria diagnosis, Gametocyte, Reverse transcription polymerase chain reaction, Plasmodium falciparum, Plasmodium vivax, Pfs25, Pvs25

\section{Background}

Gametocytes, the precursors of male and female gametes, of malaria parasites are formed in the human host through the developmental switch from asexual replication in erythrocytes. Although gametocytes are not responsible for clinical symptoms, they ensure the transmission of malaria to another host. Upon taking a blood meal, gametocytes

\footnotetext{
*Correspondence: jongwutiwes@gmail.com

Molecular Biology of Malaria and Opportunistic Parasites Research Unit, Department of Parasitology, Faculty of Medicine, Chulalongkorn University, Bangkok 10330, Thailand
}

are transferred to a mosquito's midgut lumen where they differentiate into male and female gametes. After complete sexual reproduction and successive processes of sporogonic development, mature sporozoites accumulate in the vector's salivary gland, ready to be inoculated into a new host. Therefore, the presence of gametocytes in circulation of infected individuals is imperative for malaria to remain endemic in a given community. Malaria control strategies aiming at interruption of the malaria transmission process require knowledge on the status of gametocyte carriage in each endemic area [1]. 
During acute malaria infection, the number of gametocytes in circulation of patients occurs at much lower densities than asexual stages and usually circulates at the level close to or below microscopic detection threshold, making it liable to be undiagnosed by microscopy $[2,3]$. Several epidemiological surveys have shown that only a subset of malaria-infected individuals possessed gametocytes upon microscopic examination of the blood smears [3-7]. Importantly, these gametocyte-negative blood samples remain infective to anopheline vectors akin to those that have patent gametocytaemia [6-8]. On the other hand, molecular detection of Plasmodium gametocytes has revealed that a considerable number of malaria patients whose blood samples were gametocyte-negative by microscopy actually had sub-microscopic gametocytaemia [3-7]. Therefore, microscopy detection of gametocytes could underestimate and thereby mislead evaluation of malaria transmission potential in endemic areas.

Molecular diagnostics of malarial gametocytes are based on amplification of mRNA transcripts that are exclusively expressed during gametocyte stages. Some of these transcripts are synthesized in co-ordination with specific periods of gametocyte development while some are sex-specific $[9,10]$. Therefore, specific mRNA transcripts could serve as appropriate markers for diagnosing stages of gametocytes. Of these, transcription of Pfs 25 begins when gametocytes of Plasmodium falciparum become mature (stage V) and continues until the formation of ookinetes [11]. Importantly, homologues of $P f s 25$ have been identified in several other malaria, e.g. Pvs25, Pbs25, Pgs25 and Pys25 in Plasmodium vivax, Plasmodium berghei, Plasmodium gallinaceum and Plasmodium yoelii, respectively [12]. To date, molecular epidemiological studies have been largely performed to assess $P$. falciparum gametocyte carriage because it is the most prevalent and most pernicious malaria species that requires urgent effective control measures. On the other hand, a few reports have demonstrated molecular application for diagnosing $P$. vivax gametocytes $[5,13]$ despite the fact that it is the most widely distributed species with relapsing potential and is responsible for an important global public health burden [14].

Both $P$. falciparum and $P$. vivax are major malaria species and sympatric in several endemic areas outside Africa [15]. Therefore, epidemiological surveillance or assessment of malaria transmission by estimation of both $P$. falciparum and $P$. vivax gametocyte carriage in each endemic area is essential for malaria control policy. Because the expense of reagents and turnaround time in multiplex PCR are less than single PCR, a multiplexnested RT-PCR assay targeting Pfs 25 and Pvs 25 is developed for rapid detection and differentiation of P. falciparum and $P$. vivax gametocytes simultaneously. Diagnostic performance of the method was evaluated using blood samples collected during both high and low transmission seasons from malaria patients in an endemic area of Thailand.

\section{Methods}

\section{Clinical sample collection and study area}

Blood samples $(\sim 1 \mathrm{~mL})$ were collected from 235 febrile patients (136 males and 99 females; mean age 21.7 years, range seven to 77 years) who attended a malaria clinic at Umpang District in Tak Province (GPS N16 $1^{\circ} 0^{\prime \prime}$, E9 $8^{\circ}$ $\left.51^{\prime} 46^{\prime \prime}\right)$, north-western Thailand bordering Myanmar, during the rainy season (from June to August 2010) and the dry season (from November 2010 to January 2011). All except one patient had febrile onset one day prior to blood sample collection. In total, 157 patients had malaria in their circulation based on microscopic diagnosis of Giemsa-stained blood smears. Malaria was not found by microscopy in the remaining 78 febrile individuals. Each blood sample was divided and preserved separately in EDTA and RNAlater ${ }^{\mathrm{TM}}$ (Ambion, USA). Exclusion criteria were those having previous anti-malarial treatment or presence of clinical signs and symptoms of severe malaria [16]. Informed consent was obtained from each patient or from a parent or guardian for those aged less than 18 years. The ethical aspects of this study have been approved by the Institutional Review Board of Faculty of Medicine, Chulalongkorn University.

\section{Microscopy}

Both thin and thick blood smears were prepared from each patient and stained with Giemsa solution for microscopic diagnosis of malaria species and stages. Parasite density was assessed from a thick blood film for $\geq 200$ leukocytes with a $100 \times$ objective. Estimation of parasite density was performed by assuming a standard count of 7,000 leucocytes/ $\mu \mathrm{L}$ [17]. Each stained slide was examined independently by two microscopists who were blinded to each other results. The mean values of parasite density were used for further analysis.

\section{DNA and RNA extraction}

DNA was extracted from $200 \mu \mathrm{L}$ of EDTA-preserved blood samples using QIAGEN kit following the instruction protocol except for elution with $30 \mu \mathrm{L}$ TE buffer. Blood samples $(200 \mu \mathrm{L})$ preserved in RNAlater ${ }^{\mathrm{TM}}$ were used for RNA extraction using QIAamp RNA blood mini kit (Qiagen, Germany) and eluted with $30 \mu \mathrm{L}$ of RNase-free water. cDNA was generated from two $\mu \mathrm{L}$ of each RNA sample and amplified by using Takara RNA PCR kit (AMV) version 3.0 (Takara, Japan) in a total volume of $10 \mu \mathrm{L}$. Two $\mu \mathrm{L}$ of RNA products of each sample were used as template during subsequent PCR assay to exclude possible genomic DNA contamination in cDNA templates. 


\section{Diagnosis of malaria species by nested PCR}

Nested PCR targeting the small subunit ribosomal RNA gene (18S rRNA PCR) of all four human malaria species and. Plasmodium knowlesi was done following protocol and amplification conditions as described previously $[18,19]$. Results were obtained from $2 \%$ agarose gel electrophoresis, stained with ethidium bromide solution and visualized under UV transillumination.

\section{Positive and negative controls}

Positive controls for $P f_{s} 25$ were genomic DNA and cDNA of a clinical isolate that contained 315 mature $P$. falciparum gametocytes $/ \mu \mathrm{L}$. For Pvs 25 , genomic DNA and cDNA of a P. vivax clinical isolate harbouring 385 mature $P$. vivax gametocytes $/ \mu \mathrm{L}$ were used as positive controls. Verification of single species infection in these control samples was done by using $18 S$ rRNA PCR. Sterile water was used as negative control.

\section{Multiplex-nested RT-PCR targeting Pfs25 and Pvs25}

Primers for primary PCR (primers FV25F0 and FV25R0) were used to amplify both $P f s 25$ and $P v s 25$ and those for secondary PCR were specific to each Plasmodium species (Table 1). Secondary PCR was performed using primers F25F1 and F25R1 specific for Pfs25 and primers V25F1 and V25R1 specific for Pvs25 in the same reaction tubes. Optimization of PCR was performed by adjustment of thermal cycler profiles and concentration of primers to obtain a final condition that provided good intensities for both amplicons without non-specific bands. The optimal DNA amplification was carried out in a total volume of $20 \mu \mathrm{L}$ containing $2 \mu \mathrm{L}$ of cDNA template, $2.5 \mathrm{mM}$ each deoxynucleotide triphosphate, 2 $\mu \mathrm{L}$ of 10x PCR buffer, $1.6 \mu \mathrm{L}$ of $25 \mathrm{mM} \mathrm{MgCl}_{2}, 0.08 \mu \mathrm{L}$ of $30 \mu \mathrm{M}$ of each primer for primary PCR and 0.4 units of rTaq DNA polymerase (Takara, Seta, Japan). Thermal cycler profile for primary PCR contains $94^{\circ} \mathrm{C}$ for $1 \mathrm{~m}$ for one cycle; $94^{\circ} \mathrm{C}$ for $40 \mathrm{~s}, 55^{\circ} \mathrm{C}$ for $30 \mathrm{~s}$ and $72^{\circ} \mathrm{C}$ for $30 \mathrm{~s}$ for 25 cycles; and $72^{\circ} \mathrm{C}$ for $5 \mathrm{~m}$ for one cycle. Secondary PCR contained similar reaction mixtures except that $0.06 \mu \mathrm{L}$ of $30 \mu \mathrm{M}$ of each secondary PCR primer and 1 $\mu \mathrm{L}$ of primary PCR product as template were used. A total of 26 amplification cycles were used for secondary PCR. The amplification products were analysed by $2 \%$ agarose gel electrophoresis.

\section{Detection of Pfs 25 and Pvs25 by single-nested RT-PCR}

The PCR primers and amplification conditions for single-nested RT-PCR were essentially the same as those for multiplex-nested RT-PCR except that secondary PCR was performed in separate reaction tubes for each pair of primers. The number of amplification cycles for primary PCR and secondary PCR were essentially the same as single-nested PCR assays.

\section{Detection limit and specificity}

To estimate the detection limit of the developed methods, the entire Pfs 25 using primers PFS25F0, 5'ATGAATAAACTTTACAGTTTG-3" (nucleotides 7595, positions after GenBank ${ }^{\mathrm{TM}}$ accession no. X07802) and PFS25R0, 5' 'TTACATTATAAAAAAGCATACTG3' (nucleotides 706-728) was amplified by PCR. Amplification condition contained $94^{\circ} \mathrm{C}$ for $1 \mathrm{~m}$; 35 cycles of $94^{\circ} \mathrm{C}$ for $40 \mathrm{~s}, 53^{\circ} \mathrm{C}$ for $30 \mathrm{~s}$ and $72^{\circ} \mathrm{C}$ for $30 \mathrm{~s}$; and $72^{\circ} \mathrm{C}$ for $5 \mathrm{~m}$. Likewise, the entire Pvs 25 was amplified using primers PVS25F0, 5'-ATGAACTCCTACTACAGCCTC-3' (nucleotides 1-21, positions after GenBank $^{\mathrm{TM}}$ accession no. GU256271) and PVS25R0, 5'-TTATATGACGTACG AAGGGAC-3' (nucleotides 640-660) with the same amplification conditions. The PCR products of $P f s 25$ and Pvs25 comprised 654 and 660 bp (henceforth Pfs25L and Pvs25L), respectively, equivalent to $6.88 \times 10^{-7}$ and $6.94 \times 10^{-7} \mathrm{pg}$; thereby the copy number of each DNA template could be calculated. After the PCR-amplified products were gel purified, the concentration of each template was determined using the NanoDrop apparatus (Thermo Fisher Scientific, Delaware, USA). The dilutions of $1 \times 10^{6}$, $1 \times 10^{5}, 1 \times 10^{4}, 1 \times 10^{3}, 1 \times 10^{2}, 10,1$ and $0.1 \mathrm{copy} / \mu \mathrm{L}$ were used as templates for determination of the detection limit of each gene target. To test whether co-existence of $P$. falciparum and $P$. vivax could influence sensitivity of each PCR assay, artificially mixed DNA templates from both

Table 1 PCR primers used for amplification of Pfs 25 and Pvs25

\begin{tabular}{|c|c|c|c|c|}
\hline Gene target & Primers & Sequences $\left(5^{\prime} \rightarrow 3^{\prime}\right)$ & Nucleotide positions & Product size (bp) \\
\hline \multicolumn{5}{|l|}{ Primary PCR } \\
\hline \multirow[t]{2}{*}{ Pfs 25 and Pvs 25} & FV25F0 & GAAGATACATGTGAAGAAAAA & $237-257^{*}$ or $163-183 \#$ & 264 for $P$. falciparum \\
\hline & FV25R0 & ATTGGGAACTTTGCCAATA & $482-500^{*}$ or $414-432 \#$ & 270 for $P$. vivax \\
\hline \multicolumn{5}{|l|}{ Secondary PCR } \\
\hline \multirow[t]{2}{*}{ Pfs25 } & $\mathrm{F} 25 \mathrm{~F} 1$ & AAATGTGACGAAAAGACTG & $264-281^{*}$ & 201 \\
\hline & F25R1 & AGTITTAACAGGATTGCTTGTATC & $441-464^{*}$ & \\
\hline \multirow[t]{2}{*}{ Pvs25 } & V25F1 & ACCCTAGGCAAAGCATG & 202-218\# & 115 \\
\hline & V25R1 & CAAGTGTCTTCCTTCAAAGT & 298-317\# & \\
\hline
\end{tabular}

* and \# after GenBank ${ }^{\mathrm{TM}}$ accession numbers X07802 and GU256271 for Pfs25 and Pvs25, respectively. 
malaria species with substantial difference in copy numbers were assessed. Specificity of PCR assays was analysed against genomic DNA (five isolates each) of Plasmodium malariae, Plasmodium ovale and P. knowlesi. The nested RT-PCR method targeting Pfs25 with primers Pfs25-1, Pfs25-2, Pfs25-3 and Pfs25-4 developed by Babiker and colleagues was also used for evaluation [20].

\section{Data analysis}

Diagnostic performance for multiplex-nested RT-PCR was evaluated with the results from single-nested RT-PCR assay of the same cDNA templates as the gold standard. Performance indices were the number of true positive (TP), number of true negative (TN), number of false positive (FP) and number of false negative (FN). Sensitivity was expressed as $\mathrm{TP} /(\mathrm{TP}+\mathrm{FN})$ and specificity as $\mathrm{TN} /$ $(\mathrm{TN}+\mathrm{FP})$. The likelihood ratios for a positive test result were calculated as sensitivity/(1 - specificity), and for a negative test result as $(1-$ sensitivity $) /$ specificity [21]. Differences in parasite densities between gametocytepositives and gametocyte-negatives by microscopy were calculated by using the Mann-Whitney U test. A 2-tailed $p$ value of $<0.05$ is considered significance.

\section{Results}

Detection limits of single-nested RT-PCR for Pfs 25 and Pvs25

Single-nested PCR targeting Pfs 25 and Pvs 25 could amplify genomic DNA of $P$. falciparum and $P$. vivax generating products of expected sizes, i.e. 201 and $115 \mathrm{bp}$, respectively (Figure 1). Likewise, concordant results were obtained from cDNA templates generated from mRNA of these parasite species. The minimum dilutions of either $P$. falciparum or $P$. vivax genomic DNA that gave reproducible positive results were 10 copies. Neither PCR assays exhibited cross-reactivity with genomic DNA from nonmatched malaria species, indicating specificity of these tests. Meanwhile, a minimum of 100 copies was required for successful amplification of Pfs $25 \mathrm{~L}$ by the RT-PCR method developed by Babiker and colleagues [20].

\section{Detection limits of multiplex-nested RT-PCR}

The multiplex-nested RT-PCR developed herein gave single 201-bp product for $P$. falciparum and 115-bp product for $P$. vivax, identical to single-nested PCR targeting each gene. Neither cross-hybridization nor false amplification between primers for Pfs 25 and Pvs 25 was observed when both malaria DNA were used as templates. The minimum detection limits were 10 copies of template DNA and the results were reproducible in five assays with different DNA templates. The sensitivity remained unaltered when numerous amounts of DNA templates from the other malaria species were added in the reactions, e.g. 10 copies of $P$. vivax DNA mixed with

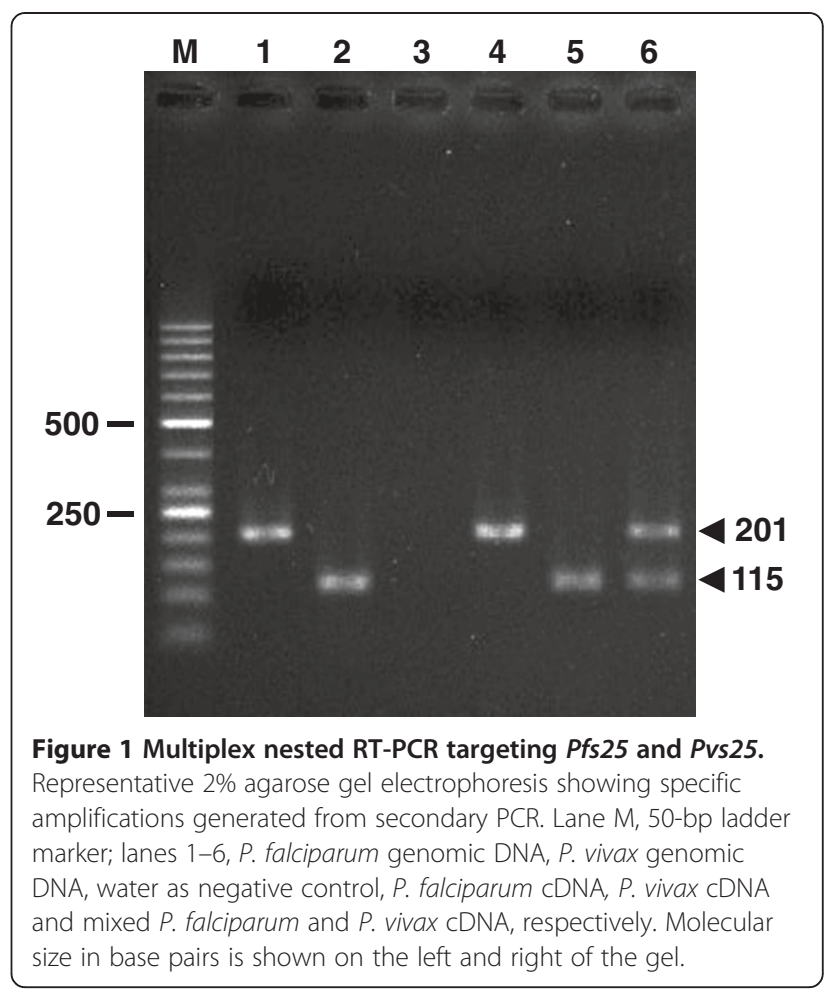

$1 \times 10^{6}$ copies of P. falciparum DNA (Table 2). Results were essentially the same when cDNA of different isolates was used as templates.

\section{Microscopy and 18S rRNA PCR diagnosis}

Malaria was microscopically diagnosed in 157 of $235 \mathrm{fe}-$ brile patients. Most patients were infected with either $P$. falciparum $(\mathrm{n}=76)$ or $P$. vivax $(\mathrm{n}=80)$. Co-infection with both species was observed in a patient. Besides asexual blood stages, $P$. falciparum gametocytes were observed in eight isolates $(8.9 \%$ of total P. falciparum-

Table 2 Detection of Pfs25 and Pvs25 in artificial mixed DNA templates by single nested RT-PCRs and multiplex nested RT-PCRs

\begin{tabular}{|c|c|c|c|c|}
\hline \multirow[t]{2}{*}{$\begin{array}{l}\text { DNA templates } \\
\text { (no. of copy) }\end{array}$} & \multicolumn{2}{|c|}{$\begin{array}{l}\text { Single nested } \\
\text { RT-PCR }\end{array}$} & \multicolumn{2}{|c|}{$\begin{array}{l}\text { Multiplex nested } \\
\text { RT-PCR }\end{array}$} \\
\hline & Pfs25 & Pvs25 & Pfs25 & Pvs25 \\
\hline$\overline{P f s} 25 L(0.1)+\operatorname{Pvs} 25 L\left(10^{6}\right)$ & - & + & - & + \\
\hline$P f s 25 L(1)+P v s 25 L\left(10^{6}\right)$ & - & + & - & + \\
\hline $\operatorname{Pfs} 25 L(10)+P v s 25 L\left(10^{6}\right)$ & + & + & + & + \\
\hline$P f s 25 L\left(10^{2}\right)+P v s 25 L\left(10^{6}\right)$ & + & + & + & + \\
\hline Pfs25L $\left(10^{5}\right)+\operatorname{Pvs} 25 L\left(10^{6}\right)$ & + & + & + & + \\
\hline $\operatorname{Pfs} 25 \mathrm{~L}\left(10^{6}\right)+\operatorname{Pvs} 25 \mathrm{~L}\left(10^{5}\right)$ & + & + & + & + \\
\hline $\operatorname{Pfs} 25 \mathrm{~L}\left(10^{6}\right)+\operatorname{Pvs} 25 \mathrm{~L}\left(10^{2}\right)$ & + & + & + & + \\
\hline Pfs25L $\left(10^{6}\right)+P v s 25 L(10)$ & + & + & + & + \\
\hline Pfs25L $\left(10^{6}\right)+\operatorname{Pvs} 25 L(1)$ & + & - & + & - \\
\hline Pfs25L $\left(10^{6}\right)+\operatorname{Pvs} 25 L(0.1)$ & + & - & + & - \\
\hline
\end{tabular}


positives by $18 S$ rRNA PCR) and $P$. vivax gametocytes in 30 isolates $(31.1 \%$ of total $P$. vivax-positives by $18 S$ rRNA PCR). Meanwhile, $18 S$ rRNA PCR gave concordant results with microscopy in 215 blood samples. Microscopy under-diagnosed 11 out of 12 patients who had co-infections with $\geq 2$ malaria species (Table 3 ). Furthermore, eight microscopy-negative samples were positive for $P$. falciparum $(\mathrm{n}=7)$ or $P$. vivax $(\mathrm{n}=1)$.

\section{Diagnostic performance of Pfs 25 and Pvs 25 mRNAs in clinical samples}

Single-nested RT-PCR targeting $P f s 25$ gave positive results in 77 blood samples $(89.5 \%$ of total $P$. falciparum positives by $18 S$ rRNA PCR) whereas 82 samples were positive for $P v s 25$, indicating the presence of mature gametocytes in these patients $(91.1 \%$ of total $P$. vivax positives by $18 S$ rRNA PCR). No amplification occurred when RNA of these isolates collected prior to cDNA synthesis was added in the assays, indicating no genomic DNA contamination. Results inferred from multiplex-

Table 3 Microscopy and molecular diagnosis of malaria species and gametocytes in $\mathbf{2 3 5}$ clinical isolates

\begin{tabular}{|c|c|c|c|}
\hline Infection & $\begin{aligned} & \text { Microscopy } 18 S \\
& r R N A \\
& \text { PCR }\end{aligned}$ & $\begin{array}{l}\text { Single } \\
\text { nested } \\
\text { RT-PCR }\end{array}$ & $\begin{array}{l}\text { Multiplex } \\
\text { nested } \\
\text { RT-PCR }\end{array}$ \\
\hline
\end{tabular}

\begin{tabular}{|c|c|c|c|c|c|c|}
\hline \multicolumn{7}{|l|}{ Monoinfection } \\
\hline P. falciparum & 76 & 75 & - & - & - & - \\
\hline Gametocyte & 8 & - & 68 & - & 67 & - \\
\hline P. vivax & 80 & 78 & - & - & - & - \\
\hline Gametocyte & 30 & - & - & 74 & - & 74 \\
\hline \multicolumn{7}{|l|}{$\underline{\text { Co-infections }}$} \\
\hline $\begin{array}{l}\text { P. falciparum } \\
\text { and } P \text {. vivax }\end{array}$ & 1 & 10 & - & - & - & - \\
\hline Gametocyte & 0 & - & 9 & 6 & 8 & 6 \\
\hline $\begin{array}{l}\text { P. vivax and } \\
\text { P. malariae }\end{array}$ & 0 & 1 & - & - & - & - \\
\hline Gametocyte & 0 & - & 0 & 1 & 0 & 1 \\
\hline $\begin{array}{l}\text { P. falciparum, } \\
\text { P. vivax }\end{array}$ & 0 & 1 & - & - & - & - \\
\hline \multicolumn{7}{|l|}{ and $P$. malariae } \\
\hline Gametocyte & 0 & - & 0 & 1 & 0 & 1 \\
\hline $\begin{array}{l}\text { Total malaria } \\
\text { positive cases }\end{array}$ & 157 & 165 & - & - & - & - \\
\hline Total P. falciparum & 77 & 86 & - & - & - & - \\
\hline Gametocyte (\%) & * $8(8.9)$ & - & 77 (89.5) & - & $75(87.2)$ & - \\
\hline Total P. vivax & 81 & 90 & - & - & - & - \\
\hline Gametocyte (\%)** & * $30(31.1)$ & - & - & $82(91.1)$ & - & $82(91.1)$ \\
\hline
\end{tabular}

* Percentage of $P$. falciparum gametocyte positives per total $P$. falciparum positives by 185 rRNA PCR.

** Percentage of $P$. vivax gametocyte positives per total $P$. vivax positives by $18 S$ rRNA PCR.

Dashes indicate no applicable data. nested RT-PCR revealed that $P$. falciparum and $P$. vivax gametocytes co-existed in four of 11 patients who were co-infected with both these malaria species (diagnosed by $18 S$ rRNA PCR). Likewise, similar results were obtained when multiplex-nested RT-PCR was applied to the same cDNA samples $(87.2 \%$ and $91.1 \%$ for P. falciparum and $P$. vivax, respectively) except that singlenested RT-PCR targeting Pfs 25 yielded two more positive results than multiplex-nested RT-PCR (Table 3). With results from single RT-PCR as standard, multiplexnested RT-PCR provided high sensitivity and specificity for amplification of $P f s 25$ and Pvs25. Furthermore, high values of likelihood ratios of positive test result (82.4 for $P v s 25$ to infinity for $P f s 25$ ) was noted whereas multiplex-nested RT-PCR offered very low values of likelihood ratios of negative test results (Table 4). Both single and multiplex-nested RT-PCR contributed greater efficacy for diagnosing gametocytes of P. falciparum and $P$. vivax than microscopy and the performance was more pronounced for those of P. falciparum (Table 4).

\section{Transmission seasons and gametocyte prevalence}

The prevalence of $P$. falciparum isolates containing gametocytes collected in dry season was not significantly different from that collected in wet season. Likewise, no significant seasonal difference was observed between the prevalence of isolates harbouring $P$. vivax gametocytes. These findings remain the same regardless of the methods (microscopy, single-nested RT-PCR or multiplexnested RT-PCR) deployed for gametocyte detection (Table 5). However, parasite density of $P$. vivax has significant influence on gametocyte detection by microscopy whereas this effect was not evident for $P$. falciparum (Table 6).

Table 4 Diagnostic performance of multiplex nested RTPCR for Pfs 25 and Pvs25 with single nested RT-PCR as reference

\begin{tabular}{lll}
\hline & $\begin{array}{l}\text { Gametocytes (\%) } \\
\text { P. falciparum }\end{array}$ & P. vivax \\
\hline Sensitivity & $75 / 77(97.4)$ & $81 / 82(98.9)$ \\
Specificity & $80 / 80(100)$ & $80 / 81(98.8)$ \\
Likelihood ratio of positive test & $*$ & 82.4 \\
Likelihood ratio of negative test & 0.03 & 0.01 \\
$\begin{array}{l}\text { Ratio of single nested RT-PCR } \\
\text { positives to }\end{array}$ & 9.63 & 2.73 \\
$\quad \begin{array}{l}\text { microscopy positives } \\
\text { Ratio of multiplex nested RT-PCR }\end{array}$ & 9.50 & \\
$\quad$ positives to & & \\
$\quad$ microscopy positives & & \\
* Denominator is zero. &
\end{tabular}

* Denominator is zero. 
Table 5 Prevalence of $P$. falciparum and $P$. vivax gametocytes among isolates collected in dry and wet seasons

\begin{tabular}{|c|c|c|c|c|c|}
\hline Diagnostic method & \multicolumn{2}{|c|}{ Dry season } & \multicolumn{2}{|c|}{ Wet season } & $p$ value \\
\hline \multicolumn{6}{|l|}{ Microscopy } \\
\hline P. falciparum gametocyte & 3 & 6.4 & 3 & 7.7 & 0.81 \\
\hline P. vivax gametocyte & 17 & 34 & 13 & 32.5 & 0.88 \\
\hline \multicolumn{6}{|l|}{ Single nested RT-PCR } \\
\hline P. falciparum gametocyte & 40 & 85.1 & 35 & 89.7 & 0.52 \\
\hline P. vivax gametocyte & 46 & 92 & 36 & 90 & 0.74 \\
\hline \multicolumn{6}{|l|}{ Multiplex nested RT-PCR } \\
\hline P. falciparum gametocyte & 42 & 89.4 & 35 & 89.7 & 0.95 \\
\hline P. vivax gametocyte & 46 & 92 & 36 & 90 & 0.74 \\
\hline \multicolumn{6}{|l|}{185 rRNA PCR } \\
\hline P. falciparum & 47 & - & 39 & - & - \\
\hline P. vivax & 50 & - & 40 & - & - \\
\hline
\end{tabular}

* total number of positives for a given species by $18 S$ rRNA PCR. - denotes not applicable.

\section{Discussion}

Recent molecular epidemiological surveys of malaria in Thailand have revealed that all five Plasmodium species circulate in this country. Most malaria cases are caused by $P$. falciparum ( $56.8 \%$ of all species) and $P$. vivax $(\sim 41.3 \%)$. It is noteworthy that co-infections of both these species contributed $\sim 12.5 \%$ of all malaria cases; the highest prevalence of $\sim 23-24 \%$ occurred along the

Table 6 Parasite densities of isolates with monoinfections of $P$. falciparum and of $P$. vivax collected in dry and in wet seasons

\begin{tabular}{|c|c|c|}
\hline \multirow[t]{2}{*}{ Category } & \multicolumn{2}{|c|}{ Parasite density (parasites $/ \mu \mathrm{L}$ ) } \\
\hline & Dry season & Wet season \\
\hline \multicolumn{3}{|l|}{ P. falciparum* } \\
\hline with gametocyte & $n=3$ & $n=5$ \\
\hline range & $1560-7000$ & $930-36630$ \\
\hline median & 2960 & 6695 \\
\hline no gametocyte & $n=40$ & $n=27$ \\
\hline range & $0-288360$ & $0-110840$ \\
\hline median & 22280 & 17800 \\
\hline \multicolumn{3}{|l|}{$\frac{\text { P. vivax }}{}$} \\
\hline with gametocyte & $n=17$ & $n=11$ \\
\hline range & 11640-70080 \# & 6090-49320 \# \\
\hline median & 19360 & 9630 \\
\hline no gametocyte & $n=29$ & $n=21$ \\
\hline range & $0-36360$ & $304-16360$ \\
\hline median & 6560 & 2740 \\
\hline
\end{tabular}

* Verification of monoinfection by 185 rRNA PCR.

\# Parasite densities between isolates with and without detectable gametocytes by microscopy were significantly different $(p<0.001$, MannWhitney $U$ test).
Thailand and Myanmar borders [18,19]. Therefore, malaria control by transmission-reducing interventions, such as gametocytocidal drugs or sexual stage vaccines, requires simultaneous assessment of human infectious reservoirs of both Plasmodium species. The multiplexnested RT-PCR developed herein offered high diagnostic performance with sensitivity and specificity over 97\% when results from single-nested RT-PCR targeting each of these transcripts were used as standard. Multiplexnested RT-PCR detected gametocytes of $P$. falciparum and $P$. vivax 9.50 and 2.73 times more patient samples, respectively, than was determined by microscopy. It is noteworthy that $87.4 \%$ of $P$. falciparum and $91.1 \%$ of $P$. vivax clinical isolates in Umpang District contained gametocytes based on detection of Pfs 25 and Pvs 25 mRNA by multiplex-nested RT-PCR and total malaria species identified by $18 S$ rRNA PCR. Similarly, molecular surveys in Kenya and Tanzania revealed $89.3-92.3 \% P$. falciparum gametocyte prevalence despite differences in disease endemicity between these countries and Thailand [22]. The high prevalence of submicroscopic gametocyte carriage has been hypothesized to ensure gametocyte survival by avoiding substantial stimulation for anti-gametocyte immune responses $[23,24]$ and developmental success in vector by preventing damage of mosquito midgut during ookinete invasion through oocyst development [24-26].

A recent study using $P$. falciparum isolates from patients in Tak Province who had febrile symptom $\sim 3$ days (range one to eight days) before blood sample collection $(n=44)$ revealed that all isolates gave positive results for RT-PCR targeting Pfg377, a female gametocyte-specific mRNA, whereas microscopy detected gametocytes in only six isolates. Subsequent in vitro cultivation resulted in gametocyte production in $89 \%$ of isolates as detected by microscopy [27]. Meanwhile, all except one malaria patients in this study had fever one day prior to blood sample collection. Although it is likely that there could be some expression of $P v s 25$ and $P f s 25$ at the early stages of gametocyte maturation, probably from leaky transcription or low-level transcription, Pvs 25 and Pfs $25 \mathrm{mRNA}$ in blood samples are mainly from mature gametocytes. Taken together, it seems that almost all patients infected with P. falciparum in Tak province had mature gametocytaemia within a few days after onset of febrile symptoms albeit the majority existing below microscopic detection threshold. Likewise, similar findings were demonstrated in $P$. vivax-infected patients, suggesting that malaria transmission could occur at the beginning or soon after the febrile onset in this endemic area. By contrast, a survey of $P$. falciparum gametocytes among patients in an endemic area in Tak Province by RT-PCR using the method described by Babiker et al has shown only 15 of 
82 samples (18.3\%) contained Pfs 25 mRNA whereas reverse transcriptase-loop-mediated isothermal amplification (RT-LAMP) provided slightly superior results (29.2\%) [28]. Discrepancy in prevalence of gametocyte carriage may not be directly compared between studies because of non-identical clinical samples and methodology. However, there remains a possibility that the detection methods conferred different diagnostic sensitivity. Importantly, the minimum diagnostic threshold of the multiplex-nested RT-PCR in this study was 10 copies of templates. Although estimation of detection limit of the multiplex-nested RT-PCR in this study did not directly reflect the actual number of gametocytes in the samples, it is likely that each mature gametocyte of $P$. falciparum or $P$. vivax possesses several copies of Pfs 25 mRNA or Pvs 25 mRNA; thereby a single gametocyte is potentially sufficient to give a positive result.

It has been noted that P. falciparum gametocyte carriage is more common in areas with high malaria transmission intensity and the younger age group seems to have higher gametocyte prevalence than in an older age group. However, age-dependent patterns of gametocyte carriage for $P$. falciparum and $P$. vivax have not been documented in this study, consistent with previous findings that in areas with low transmission intensity, age groups of infected individuals seem not to be apparently associated with gametocyte prevalence [29-31]. Meanwhile, the prevalence of gametocyte carriage relative to all malaria cases as detected by either microscopy or multiplex-nested RT-PCR in this study seems to show no significant seasonal fluctuation as previously noted $[32,33]$. Discrepancy could arise from the small sample size in this study, differences in intensity of malaria exposure among subjects, competency of routine microscopists in diagnosing gametocytes of $P$. vivax or other unknown factors. Nevertheless, the high prevalence of gametocyte carriage detected by multiplex-nested RTPCR for both $P$. falciparum and $P$. vivax in both high (wet season) and low (dry season) transmission periods could ensure sustainability of malaria endemicity in the study population.

The prevalence of individuals with gametocytaemia based on microscopy showed remarkable spatial variation. However, sensitivity of gametocyte detection by microscopy per se could be influenced by the experience of microscopists, the quality of slide preparation and the number of microscopic fields examined [1-3]. Herein, patients who carried microscopically patent $P$. vivax gametocytaemia had significantly higher median parasite density than those without detectable gametocytes by microscopy. Therefore, a higher parasite density may offer a better chance for detecting gametocytes of $P$. vivax prior to anti-malarial treatment. Importantly, a number of factors could influence microscopically patent gametocytaemia, e.g. exposure to anti-malarial drugs, increased in body temperature or anaemia [1]. These constraints, compromising effective assessment of gametocyte carriage, could be alleviated by deployment of RT-PCR-based methods for detecting gametocytespecific mRNA with remarkably higher sensitivity than conventional microscopy. Because the patterns and dynamics of gametocyte carriage in malaria-infected individuals have important contributions to the capability of malaria transmission and persistence in each endemic area, simultaneous detection of both $P$. falciparum and $P$. vivax gametocytaemia by multiplex-nested RT-PCR developed herein will be useful in areas where both malaria species co-circulate.

\section{Competing interests}

The authors declare that they have no competing interests.

\section{Authors' contributions}

SJ and CP involved in study design, supervised and managed the project. NK, CP, UP and SJ carried out field work. NK, SJ and CP carried out molecular assay. NK and UP performed microscopy-based detection and estimation of parasite density. NK, CP and SJ analysed data. SJ and CP wrote the manuscript. All authors read and approved the final manuscript.

\section{Acknowledgements}

We are grateful to all patients who participated in this study and to Charoenchai Ungjaroensuk and staff at malaria clinic, Division for Diseases Control, Ministry of Public Health for assistance in field works. This study was supported by grants from the National Research Council of Thailand to S.J and C.P. (grant for fiscal years 2008-2009); Graduate School Thesis Grant (academic year 2011) and Molecular Biology of Malaria and Opportunistic Parasites Research Unit, Chulalongkorn University.

Received: 17 February 2012 Accepted: 18 May 2012

Published: 10 June 2012

\section{References}

1. Bousema T, Drakeley C: Epidemiology and infectivity of Plasmodium falciparum and Plasmodium vivax gametocytes in relation to malaria control and elimination. Clin Microbiol Rev 2011, 24:377-410.

2. Dowling MA, Shute GT: A comparative study of thick and thin blood films in the diagnosis of scanty malaria parasitemia. Bull World Health Organ 1966, 34:249-267.

3. Karl S, Davis TM, St. Pierre TG: A comparison of the sensitivities of detection of Plasmodium falciparum gametocytes by magnetic fractionation, thick blood film microscopy, and RT-PCR. Malar J 2009, 8:98.

4. Maeno Y, Nakazawa S, Dao LD, Yamamoto N, Giang ND, Hanh VT, Thuan LK, Taniguchi K: A dried blood sample on filter paper is suitable for detecting Plasmodium falciparum gametocytes by reverse transcription polymerase chain reaction. Acta Trop 2008, 107:121-127.

5. Beurskens M, Mens P, Schallig, Syafruddin D, Asih PBS, Hermsen R: Quantitative determination of Plasmodium vivax gametocytes by realtime quantitative nucleic acid sequence-based amplification in clinical samples. AmJTrop Med Hyg 2009, 81:366-369.

6. Nwakanma D, Kheir A, Sowa M, Dunyo S, Jawara M, Pinder M, Milligan P, Walliker D, Babiker HA: High gametocyte complexity and mosquito infectivity of Plasmodium falciparum in the Gambia. Int J Parasitol 2008, 38:219-227.

7. Ouedraogo AL, Bousema T, Schneider P, de Vlas SJ, Ilboudo-Sanogo E, Cuzin-Ouattara N, Nebie I, Roeffen W, Verhave JP, Luty AJF, Sauerwein R: Substantial contribution of submicroscopical Plasmodium falciparum gametocyte carriage to the infectious reservoir in an area of seasonal transmission. PloS One 2009, 4:e8410. 
8. Pethleart A, Prajakwong S, Suwonkerd W, Corthong B, Webber R, Curtis C: Infectious reservoir of Plasmodium infection in Mae Hong Son Province, north-west Thailand. Malar J 2004, 3:34.

9. Baker DA: Malaria gametocytogenesis. Mol Biochem Parasitol 2010, 172:57-65.

10. Pradel G: Proteins of the malaria parasite sexual stages: expression, function and potential for transmission blocking strategies. Parasitol 2007, 134:1911-1929.

11. Kaslow DC, Quakyi IA, Syin C, Raum MG, Keister DB, Coligan JE, McCutchan TF, Miller $L H$ : A vaccine candidate from the sexual stage of human malaria that contains EGF-like domains. Nature 1988, 333:74-76.

12. Alano P, Billker O: Gametocytes and gametes. In Molecular approches to malaria. 1st edition. Edited by Sherman IW. Washington DC: ASM Press; 2005:191-219.

13. Bharti AR, Chuquiyauri R, Brouwer KC, Stancil J, Lin J, llanos-Cuentas A Vinetz JM: Experimental infection of the neotropical Anopheles darlingi by human patient-derived the peruvian Amazon. AmJTrop Med Hyg 2006, 75:610-616.

14. Price RN, Tjitra E, Guerra CA, Yeung S, White NJ, Anstey NM: Vivax malaria: Neglected and not benign. AmJTrop Med Hyg 2007, 77:79-87.

15. Hay SI, Guerra CA, Tatem AJ, Noor AM, Snow RW: The global distribution and population at risk of malaria: past, present, and future. Lancet Infect Dis 2004, 4:327-336.

16. World Health Organization: Severe falciparum malaria. Trans Roy Soc Trop Med Hyg 2000, 94(Suppl):1-90.

17. Kain KC, Brown AE, Mirabelli L, Webster HK: Detection of Plasmodium vivax by polymerase chain reaction in a field study. J Infect Dis 1993, 168:1323-1326.

18. Putaporntip C, Hongsrimuang T, Seethamchai S, Kobasa T, Limkittikul K, Cui $L$, Jongwutiwes S: Differential prevalence of Plasmodium infections and cryptic Plasmodium knowlesi malaria in humans in Thailand. $J$ Infect Dis 2009, 199:1143-1150.

19. Jongwutiwes $S$, Buppan $P$, Kosuvin R, Seethamchai S, Pattanawong U, Sirichaisinthop J, Putaporntip C: Plasmodium knowlesi malaria in humans and macaques, Thailand. Emerg Infect Dis 2011, 17:1799-1806.

20. Babiker HA, Abdel-Wahab A, Ahmed S, Suleiman S, Ranford-Cartwright L, Carter R, Walliker DA: Detection of low level Plasmodium falciparum gametocytes using reverse transcriptase polymerase chain reaction. $\mathrm{Mol}$ Biochem Parasitol 1999, 99:143-148.

21. Jaeschke RG, Guyatt G, Sackett DL: Users' guides to the medical literature. III. How to use an article about a diagnostic test. A. Are the results of the study valid? JAMA 1994, 271:389-391.

22. Bousema T, Okell L, Shekalaghe S, Griffin JT, Omar S, Sawa P, Sutherland C, Sauerwein R, Ghan A, Drakeley C: Revisiting the circulation time of Plasmodium falciparum gametocytes: molecular detection methods to estimate the duration of gametocyte carriage and the effect of gametocytocidal drugs. Malar J 2010, 9:136.

23. Taylor LH, Read AF: Why so few transmission stages? Reproductive restraint by malaria parasites. Parasitol Today 1997, 13:135-140.

24. Saeed M, Roeffen W, Alexander N, Drakeley CJ, Targett GAT, Sutherland CJ: Plasmodium falciparum antigens on the surface of the gametocyteinfected erythrocyte. PLoS One 2008, 3:e2280.

25. Klein TA, Harrison BA, Grove JS, Dixon SV, Andre RG: Correlation of survival rates of Anopheles dirus A (Diptera: Culicidae) with different infection densities of Plasmodium cynomolgi. Bull World Health Organ 1986, 64:901-907.

26. Maier WA, Becker-Feldman H, Seitz HM: Pathology of malaria-infected mosquitoes. Parasitol Today 1987, 3:216-218.

27. Nakazawa S, Culleton $R$, Maeno $Y$ : In vivo and in vitro gametocyte production of Plasmodium falciparum isolates from northern Thailand. Int J Parasitol 2011, 41:317-323.

28. Buates S, Bantuchai S, Sattabongkot J, Han ET, Tsuboi T, Udomsangpetch R, Sirichaisinthop J, Tan-ariya P: Development of a reverse transcription-loopmediated isothermal amplification (RT-LAMP) for clinical detection of Plasmodium falciparum gametocytes. Parasitol Int 2010, 59:414-429.

29. Bousema JT, Drakely CJ, Sauerwein RW: Sexual-stage antibody responses to P. falciparum in endemic populations. Curr Mol Med 2006, 6:223-229.

30. Graves PM, Burkot TR, Carter R, Cattani JA, Lagog M, Parker J, Brabin BJ, Gibson FD, Bradley DJ, Alpers MP: Measurement of malarial infectivity of human populations to mosquitoes in the Madang area, Papua New Guinea. Parasitol 1988, 96:251-263.
31. Shekalaghe SA, Bousema JT, Kunei KK, Lushino P, Masokoto A, Wolters LR, Mwakalinga S, Mosha FW, Sauerwein RW, Drakeley CJ: Submicroscopic Plasmodium falciparum gametocyte carriage is common in an area of low and seasonal transmission in Tanzania. Trop Med Int Health 2007, 12:547-553.

32. Drakely C, Sutherland C, Bousema JT, Sauerwein RW, Targett GA: The epidemiology of Plasmodium falciparum gametocytes: weapons of mass dispersal. Trends Parasitol 2006, 22:424-430.

33. Nacher M, Carrara VI, McGready R, Ashley E, Nguen JV, Thwai KL, Looareesuwan S, Nosten F: Seasonal fluctuations in the carriage of Plasmodium vivax gametocytes in Thailand. Ann Trop Med Parasitol 2004, 98:115-120

\section{doi:10.1186/1475-2875-11-190}

Cite this article as: Kuamsab et al.: Simultaneous detection of Plasmodium vivax and Plasmodium falciparum gametocytes in clinical isolates by multiplex-nested RT-PCR. Malaria Journal 2012 11:190.

\section{Submit your next manuscript to BioMed Central and take full advantage of:}

- Convenient online submission

- Thorough peer review

- No space constraints or color figure charges

- Immediate publication on acceptance

- Inclusion in PubMed, CAS, Scopus and Google Scholar

- Research which is freely available for redistribution 